\title{
On Nike's Homosexual Tendency from the Perspective of Unconscious Theory
}

\author{
Siyou Zhang ${ }^{1, \text { a }}$, Jin Huang ${ }^{1}$ \\ ${ }^{1}$ Wuhan University of Science and Technology, Wuhan, Hubei Province, China \\ a1585143263@qq.com
}

Keywords: Nike; unconsciousness; paradox character; homosexual tendency.

\begin{abstract}
The Great Gatsby is one of the bright stars in American literature, whose writer, Francis Scott Fitzgerald, is also one of the greatest writers in the early 20th century in America. His works give people much enlightenment; reveal the real American society then. So, we can say that Fitzgerald is a mirror of American society in the early 20th century. The thesis is using unconscious theory of psychological school to analyze the character of a special role in the novel - Nike. The author is trying to find the origin of Nike's "paradox" behavior, meanwhile, to reveal the origin of the tragic in this novel.
\end{abstract}

\section{Introduction}

Francis Scott Fitzgerald (1896-1940) is one of the most outstanding authors in the history of American literature, as well as a famous American playwriter and the most significant representative in "Jazz Age". Each of his works is the crystallization of a successful poet and a playwriter's sensitive imagination. Among them, The Great Gatsby is considered as Fitzgerald's best work, either in terms of the thought depth or in the intensity of artistic expression [1].

The Great Gatsby mainly tells the story of a young man - Gatsby who is abandoned by his first love, Daisy. In order to restore their love, Gatsby uses illegal means to obtain a lot of wealth. He also holds lavish parties to draw by Daisy's attention. Although he is in the upper class, he is still a misfit with them. Finally he is on to destruction. This work is described, planned and commented by Nike. Therefore, Nike plays a pivotal role in the whole work. The previous papers mainly focused on Nike's identity and role. This paper adopts unconscious theory of psychoanalysis and analyzes Nike's paradox behaviors. Sometimes Nike is fair and decent; while sometimes he is narrow and extreme. His paradox behaviors promote the development of the whole story.

\section{General Introduction of Unconscious Theory}

"Unconsciousness" is the core idea of an Austrian psychologist, Sigmund Freud who proposed psychoanalysis. Unconsciousness and consciousness are psychologically opposite. Consciousness refers to everything that an individual perceive through thoughts, memories, or recall, etc. Unconsciousness is the opposite, which refers to everything that an individual cannot perceive through thoughts, memories, or recall, etc. In the present paper, unconsciousness is not only a psychological term, but a term with linguistics and literary definition which is based on psychology. Unconsciousness mainly refers to everything that are resisted and repressed by social norms and customs, which cannot be transformed into consciousness. They are mainly the desires that cannot be allowed by social customs, habits, morality and laws. These desires are suppressed by sensibility while an individual is sober. Thus, they are not revealed. But these desires conflict with other social customs, morality and laws. The individuals hide the impermissible desire at an unconscious level through self-regulation. However, these conflicts have not been resolved. The individuals would unconsciously do something to satisfy their desires. This is the right unconscious theory proposed by Freud: an individual's behavior will be affected by his unconsciousness, which would also subtly influence the development of an individual's behaviors. 
Freud pointed out that the unconscious influence of individual behavior is primarily gained by sexual desire which would satisfy his desire. An individual's main desire is sexual desire [2]. This pansexualism is contradicted by his successor Jacques Lacan (1901-1981). Lacan inherited and developed Freud's unconscious theory, and made it philosophical [3]. He proposed that unconsciousness is the real element of an individual and it is manifested by the language structure. Lacan combined Freud's psychoanalysis and Saussure's theory of language structure. He supposed that unconsciousness has language structure. By studying unconscious language structure and operation regulations, we could discover the motivations and purposes of human's language and behavior [4].

Similarly, the study of human's language and behavior can also reveal the structure and operation regulations of unconsciousness, and resolve the motivations and purposes of individual behavior [5]. Through the study of Nike's language and behaviors, this paper reveals the unconscious structure and operation regulations of Nike's behaviors, which reveals the origin of the tragic in this novel.

\section{Analysis of Nike's Paradox Behaviors}

The Great Gatsby is a stunning work in the world. It is found in the research that Nike is the core character in this novel. He is always inextricably linked to others. He is Daisy's cousin, Tom's classmate in university, Gatsby's neighbor and friend, as well as Jordan's lover. These special character relations make Nike the best narrator, planner and reviewer of the whole story. And Nike's paradox behaviors are also formed in these relations. Nike's "justice" is mainly to Gatsby and Daisy, while his "evil" is mainly to Jordan and Tom.

Comparison of Nike's "justice" to Gatsby and "evil" to Jordan. Nike is Gatsby's neighbor and friend. He is always interested in this mysterious neighbor, Gatsby. Though he had never seen Gatsby, he has been paying attention to him. He only knew Gatsby is a very wealthy man and always holds a party, but he has never seen Gatsby, which makes Nike much more curious. Finally, in Gatsby's last evening, Nike saw him. Nike has been admired him for a long time. For Nike, Gatsby is an excellent young man. He greatly admires Gatsby's life pursuit and attitude. After knowing Gatsby and Daisy's previous story, he strongly contributed to their gathering. In fact, Nike's obsession with Gatsby has exceeded the normal scope of a friend. He has been quietly focusing on Gatsby's everything. Even if he knows the secret of Gatsby's wealth, he continues to support him. Even if he knows Gatsby and Daisy's previous story, he stills to promote a bilateral affair. Although Nike is fond of Gatsby, he has not received Gatsby's any emotional response. In the early 20th century in the United States, homosexuality has not been accepted. Thus, Nike has to hide his affection. Due to the inner sense and sensibility, Nike has done some behaviors, for instance, he helps Daisy and Gatsby have an affair. Nike's unconscious mind gradually makes him do behaviors which are contrary to ethical and social morality. For Gatsby, Nike is a good friend and he is generous, reliable and open-minded.

Nike's affection for Gatsby also has a profound impact on his mate conditions. Jordan, Nike's lover in this work, is physically strong and very good at golf. In fact, Jordan is the representative of female image in the new era. She changes the past elegant and beautiful femininity. On the contrary, she is strong and makes herself the center, like a man. Such Jordan is undoubtedly the best imaginary companion in the eyes of a gay. In this case, Nike could give an account to himself, to the society. After all, in that era, homosexuality has not been deeply developed. Nike's love to Gatsby cannot be accepted by the society. However, such a lover, Jordan, would undoubtedly be the best explanation. While Jordan is a good target candidate, Nike and Jordan eventually broke up. We can see that although Nike tries to follow the social morality and customs and looks for a female partner, the real Nike with homosexual tendency repels the close relation to women. It is stated in the novel that Nike has a lot of girlfriends. But once the other shows the intention to deepen the bilateral relationship, Nike will shrink back and eventually they would break up. These behaviors are actually influenced by Nike's unconsciousness. Maybe Nike himself did not realize that his affection has affected his life. For Jordan, Nike is a failed lover and he is irresponsible, unreliable and discarding.

Comparison of Nike's "justice" to Daisy and "evil" to Tom. Nike is Daisy's cousin. Daisy is Nike's cousin, Tom's wife, Gatsby's lover, and Jordan's friend. Although Daisy is very beautiful, in 
the work, Nike's description shows Daisy is mediocre, vulgar and hypocritical. She knows Tom has an affair, but she still has an indifferent attitude. The only thing she is interested in is money and material enjoyment. Even if facing to her daughter, she is not intimate enough. After killing someone while driving, she and her husband just left in a hurry. Why did Nike pay much attention to such a Daisy? It is because of Gatsby. Driven by Nike's affection for Gatsby, Nike takes care of Daisy. Thus, while knowing Daisy and Gatsby's previous story, he contributes to their affair. But in that closed era, this disgraceful affair behavior is socially disgraced. In game of social morality and inner affection, Nike chooses Gatsby again. Nike is driven by his unconsciousness again and again, which violates the social and moral regulations. But for Daisy, Nike has become a reliable cousin and he is sincere, open-minded and helpful.

Nike is also Tom's classmate. Both of Nike and Tom graduate from Yale University. But at that time, they did not know each other. Nike supposed Tom is not loyal to his marriage. He insulates vulnerable groups. He is irresponsible to his family. He always wastes money, etc. He is also not loyal to his marriage, but when he knew that Daisy and Gatsby's extramarital affairs, he becomes extremely angry, and even indirectly lead to Gatsby's death. Facing Tom's shameless behaviors, Nike tried to help Daisy leave Tom and get rid of her husband and their marriage. The moral balance in Nike hearts again tilt. In this case, Nike chooses social morality, social customs and culture, which shows his justice. But Nike does not realize that since he helped Gatsby and Daisy, they are the same to Tom. All of them are not loyal to their marriage and partner. In the Nike of unconscious state, he thinks Tom's behavior cannot be socially acceptable, but Gatsby and Daisy's behavior is the right choice. His wrong opinion is also based on his special affection for Gatsby. Tom is Gatsby's rival. Thus, for Nike, everything that could threaten Gatsby is not helpful. But Nike does not realize that what he did also destroys Tom's family and harms the interests of Tom. For Tom, Nike is an incompetent classmate and he is nosy, extreme and narrow.

\section{Conclusions}

Nike's paradox behaviors in this work have been promoting the development of the whole story. On one hand, he receives education, social morality, culture and customs; on the other hand, he cannot ignore his true feelings of Gatsby, which is beyond his control. He has to struggle in sense and sensibility. Thus, sometimes he is fair and decent; while sometimes he is narrow and extreme. He tries to keep the balance of sense and sensibility. However, the real Nike is always slightly better. His homosexuality tendency can explain almost all of his seemingly contradictory behaviors. In summary, Nike's homosexuality tendency has deeply affected his actions. His affection for Gatsby which is not accepted by the people around makes him act differently to different people, and also contributes to the development of the whole story. He is the origin of the tragic in this novel.

\section{References}

[1] WU Jianguo. Fitzgerald [M]. Shanghai: Shanghai Foreign Language Education Press. 2002: 168.

[2] XIAO Jianrong. Summary Rewriting of Lacan's Psychoanalysis on Freud's Psychoanalytic Theory [J]. Journal of Southwest Agricultural University (Social Science Edition). 2013, 11 (06): 44-47.

[3] FANG Hanwen. The Jacques Lacan's Post-Psychaoanalsysis Theory and Julia Kristeva's Poetics Discourse [J]. Journal of Sicbuan International Studies University. 2007, 23 (06): 43-47.

[4] ZHAN Junfeng. Lacanian Psychoanalysis and Studies of Cultural Identity [J]. Journal of Xi'an Foreign Languages University. 2012, 20 (01): 21-24.

[5] SONG Xiukui. Shattering of Ideal Ego: A Survey of Willy Loman's Tragedy from Lacan's Psychoanalytic Theory [J]. Shandong Foreign Language Teaching Journal. 2007 (4): 97-101. 